\title{
Wenckebach phenomenon in the bundle-branch system
}

\author{
F. Franchi, G. Morace, and F. Fantini \\ From the Department of Clinical Medicine - Cardiology Unit, University of Florence, Italy
}

Left bundle-branch block characterized by ventricular complexes with varying patterns, leading on to a Wenckebach-type second-degree atrioventricular block, is reported.

The different electrocardiographic patterns of left bundle-branch block may reflect a more or less complete block in this system owing to the alternate functioning of the two main divisions. The subsequent appearance of second-degree right bundle-branch block accompanied by third-degree left anterior division block revealed the presence of Wenckebach phenomenon in the posterior division.

A Wenckebach type of block may occur at various points in the conducting system other than the atrioventricular node. Wenckebach phenomenon has been experimentally produced in the two branches (Scherf and Shookhoff, 1925) and in the left bundle-branch divisions (Kretz and Da Ruos, 1972). Descriptions of tracings in which Wenckebach phenomenon occurs in one bundle-branch are uncommon. Recent studies of His bundle electrograms have shown Luciani-Wenckebach periods occurring distal to the His deflection (Narula and Samet, I970; Puech et al., 1970; Ranganathan et al., 1972).

In the present study we describe a case of left bundle-branch block presenting varying patterns and a series of beats interpreted as a 'concealed' Wenckebach phenomenon in the left bundle-branch system. The subsequent appearance of a 3:2 type of right bundle-branch block reveals the presence of a Wenckebach phenomenon in the posterior division.

\section{Case report}

A 58-year-old man presented with an atypical thoracic pain, which led to repeated electrocardiographic observations. Since 1964 he had shown left bundle-branch block with left axis deviation (about $-40^{\circ}$ ), and a QRS interval of 0.14 . In 1965 the left bundle-branch block showed a slight increase in the QRS interval (O.I6), with a little less pronounced axis deviation. In 1967, the tracing (Fig. I) shows two alternate patterns. One (second beat in $\mathrm{D}_{2}$ and first in $\mathrm{D}_{3}$ ) is characterized by an RS

Received 5 January 1973.

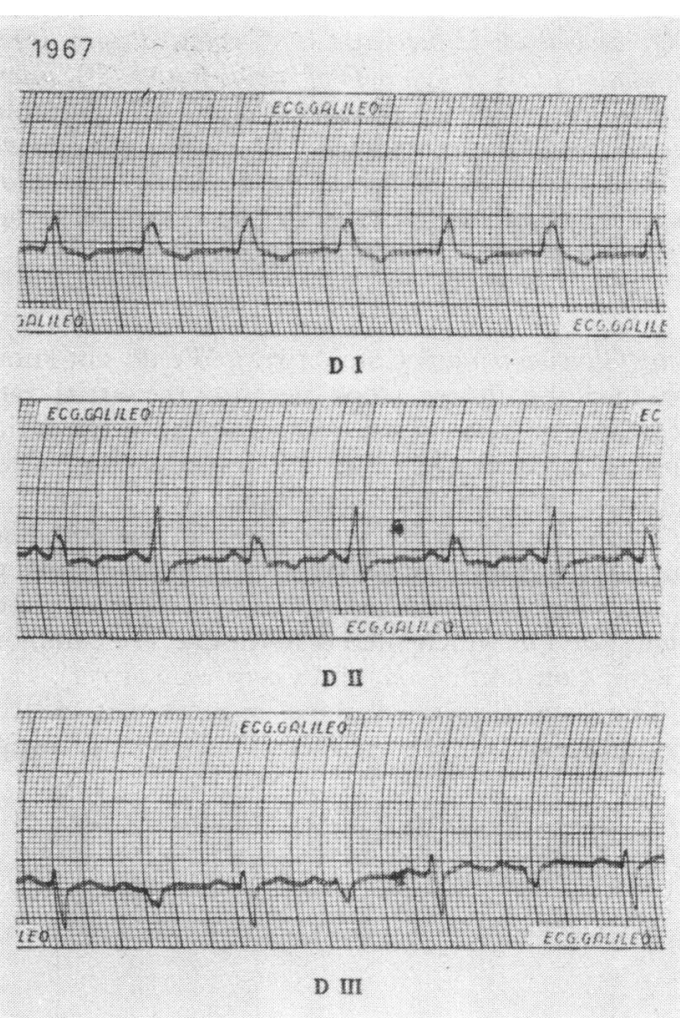

FIG. I Left bundle-branch block with two different and repetitive patterns (see text). 


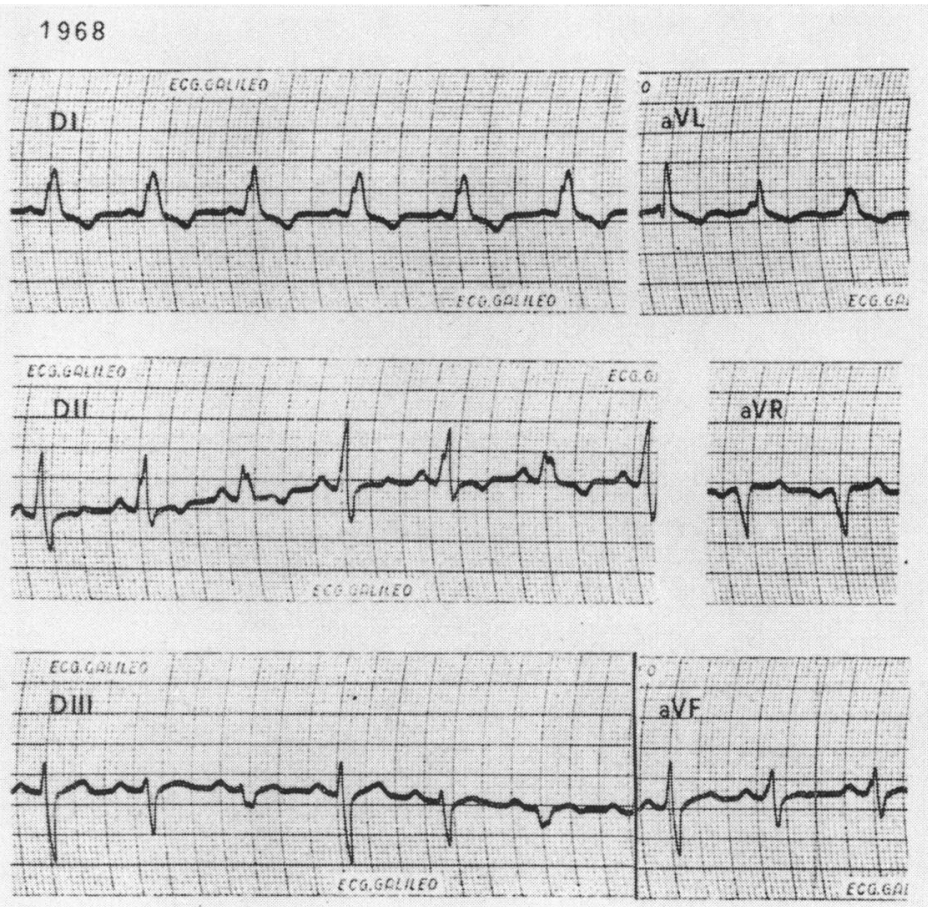

FIG. 2 Left bundle-branch block with three different and repetitive patterns (see text).

complex in $\mathrm{D}_{2}$ and an $\mathrm{rS}$ complex in $\mathrm{D}_{3}$, the other (first beat in $\mathrm{D}_{2}$ and second in $\mathrm{D}_{3}$ ) by a positive notched complex in $\mathrm{D}_{2}$ and an rs with a small slurred $s$ in $\mathrm{D}_{3}$. The former pattern corresponds to an axis deviation of about $-30^{\circ}$ and is similar to the one recorded in the 1964 electrocardiogram. The latter, which is similar to the one observed in the 1965 electrocardiogram, shows a much reduced axis deviation (about $0^{\circ}$ ). The RR intervals are constant $(660 \mathrm{msec})$. Similarly, the 1968 tracing (Fig. 2) shows sequences formed by three different patterns, which repeat regularly and are clearly differentiated, above all in $\mathrm{D}_{2}$ and $\mathrm{D}_{3}$. Two of the three patterns can be clearly seen to overlap with that recorded in 1967, while the third (first complex in $\mathrm{D}_{2}-\mathrm{D}_{3}$ ) shows a more pronounced left axis deviation (about $-45^{\circ}$ ). The tracings show constant $P R$ and $R R$ intervals.

The 1970 electrocardiogram (Fig. 3) shows the presence of a Wenckebach type second-degree atrioventricular block $(P R=0 \cdot 16-0 \cdot 20)$. The pattern of the first ventricular complex of the series is of the left anterior 'hemiblock' type (QRS=0.11; ÂQRS = about $-78^{\circ}$; intrinsicoid deflection in $\mathrm{V} 6=0.04$; Rs pattern in V6). The pattern of the second QRS is typical of a complete right bundle-branch block and a left anterior hemiblock (QRS =0.14; ÂQRS = about $-80^{\circ}$; intrinsicoid deflection in $\mathrm{Vr}=0.08$ ).

In this period brief episodes of third-degree atrio- ventricular block appeared; in 1972 a demand pacemaker had to be implanted.

\section{Discussion}

The 1967 and 1968 tracings appear to be of particular interest, if we consider the different aspects characterizing the left bundle-branch block observed in our case. These tracings show sequences of two or three different ventricular patterns, repeating regularly, all of the complete left bundle-branch block type. The changes observed in the ventricular complexes should not be attributed to respiratory movements or to variations in heart rate. It is possible that these changes in the shape of the QRS result from the fact that the complex structures of the left bundle-branch are not involved to the same degree, nor are they consistently involved, thus leading to a varying trend in the order of ventricular activation. The ventricular complexes with a more or less marked left axis deviation could reflect different degrees of completeness of the divisional bundle-branch block (Rosenbaum, Elizari, and Lazzari, 1970; Cannom, Goldreyer, and Damato, 1972). The more conspicuous deviation could, on 


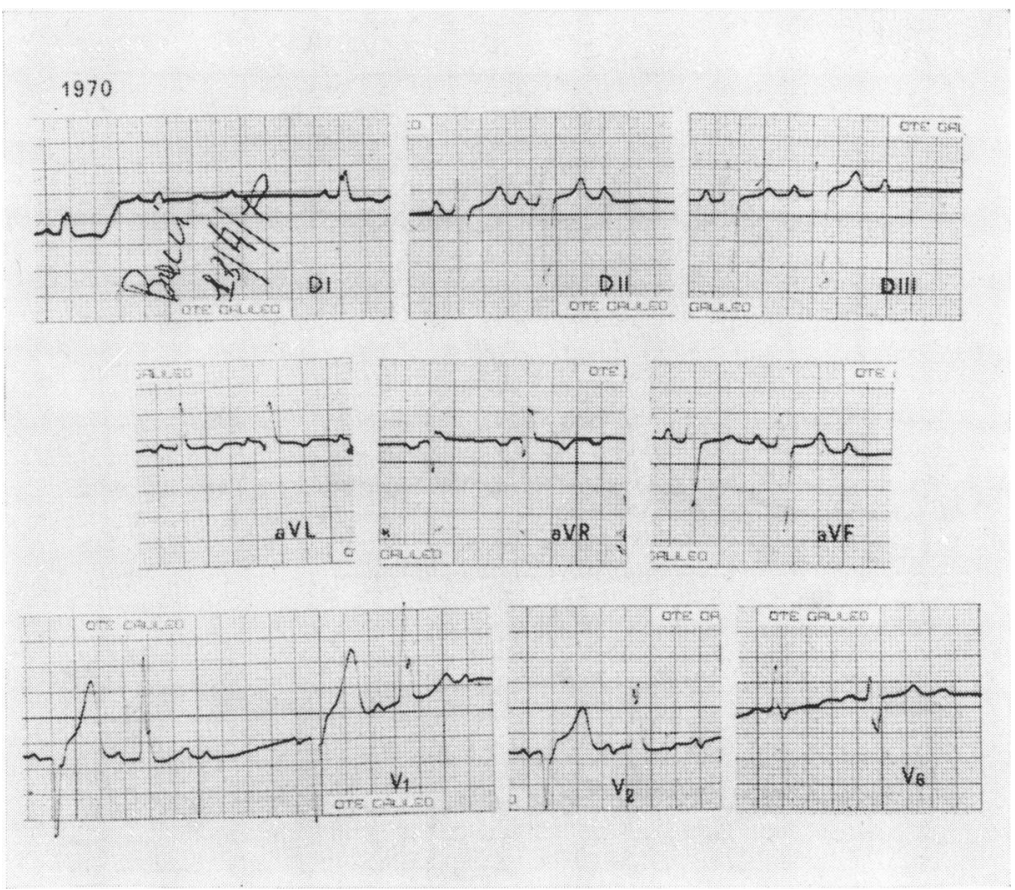

FIG. 3 Second-degree atrioventricular block (3:2) showing the Wenckebach phenomenon. The $Q R S$ complexes show two different and repetitive forms (see text).

the other hand, result from the possible concomitant conduction disturbances in the distal divisions and in the main trunk (Pryor and Blount, 1966).

The 1970 electrocardiographic sequence could be interpreted as a result of the involvement, even though of different degree, of the three divisions of the specific intraventricular conduction system. In fact, the first beat, showing the characteristics of a left anterior hemiblock, is followed by a complete right bundle-branch block type of complex, which occurs together with the preceding divisional block. This is shown by the persistent, obvious left axis deviation. Under these circumstances the atrial stimulus is conducted through the left posterior division. The increased $P R$ interval suggests that conduction along this pathway is progressively slower, and in fact the atrial impulse is blocked at the third beat of the series, the atrioventricular ratio being $3: 2$. It is therefore a seconddegree atrioventricular block, which takes place owing to the combination of a posterior division Wenckebach phenomenon, a 3:2 second-degree right bundle-branch block, and a third-degree left anterior division block.
Clinical evidence of Wenckebach phenomenon confined to one of the divisions of the left bundlebranch has seldom been reported. Rosenbaum $e t$ al. (1970) suggested this hypothesis for some types of trifascicular block $\left(\mathrm{P}_{3}, \mathrm{P}_{5}, \mathrm{P}_{7}\right.$, according to their classification). Among the clinical examples published to our knowledge is a case reported by Puech et al. (1970) showing atrioventricular block, right bundle-branch block, and left anterior hemiblock. His bundle electrograms show progressively increasing HQ intervals and normal PH intervals. The latter workers reach the conclusion that Wenckebach phenomenon probably occurs in either the distal His bundle division or in the left bundle-branch. Friedberg and Schamroth (1972) rightly quote this case as a clinical example of Wenckebach phenomenon confined to the posterior division of the left bundle. However, in the case described by Puech et al., the presence of a divisional block cannot be ascertained by means of the surface electrocardiogram, since both the PR intervals and the pattern of the ventricular complexes remain constant. In the case described by Cerqueira-Gomes and Vasconcelos Teixeira (197I), an incomplete left anterior hemiblock was accompanied by a right 
bundle-branch block and the presence of a Wenckebach phenomenon in the posterior division was suggested on the grounds of an axis deviation and of a prolonged PR interval which, we should however like to point out, was not progressively increasing. In our case not only is there a progressively increasing $P R$, but the ventricular pattern varies, owing to the simultaneous presence of an intermittent right bundle-branch block. This conduction defect and the concomitant left anterior hemiblock may allow the Wenckebach phenomenon in the posterior division, probably expressed as a 'concealed' form by the 1967 and 1968 tracings, to become 'manifest'.

\section{References}

Cannom, D. S., Goldreyer, B. N., and Damato, A. N. (1972). Atrioventricular conduction system in left bundle-branch block with normal QRS axis. Circulation, 46, 129.

Cerqueira-Gomes, M., and Vasconcelos Teixeira, A. (I97I). Wenckebach phenomenon in the posterior division of the left branch. American Heart fournal, 82, 377.

Friedberg, H. D., and Schamroth, L. (1972). Concealed
Wenckebach phenomena in the left bundle-branch. British Heart fournal, 34, 370.

Kretz, A., and Da Ruos, H. O. (1972). Experimental LucianiWenckebach phenomenon in the anterior and posterior divisions of the left bundle-branch of the canine heart. American Heart fournal, 84, 513.

Narula, O. S., and Samet, P. (1970). Wenckebach and Mobitz type II A-V block due to block within the His bundle and bundle branches. Circulation, 41, 947.

Pryor, R., and Blount, S. G. (I966). The clinical significance of true left axis deviation. Left intraventricular blocks. American Heart fournal, 72, 391.

Puech, P., Grolleau, R., Latour, H., Dufoix, R., Cabasson, J., and Robin, J. (1970). L'enregistrement de l'activité électrique du faisceau de His dans les blocs A-V spontanés. Archives des Maladies du Coeur et des Vaisseaux, 63, 784 .

Ranganathan, N., Dhurandhar, R., Phillips, J. H., and Wigle, E. D. (1972). His bundle electrogram in bundle-branch block. Circulation, 45, 282.

Rosenbaum, M. B., Elizari, M. V., and Lazzari, J. O. (1970). The Hemiblocks. Tampa Tracings, Oldsmar, Florida.

Scherf, D., and Shookhoff, C. (1925). Reizleitungsstorungen im Bundel: II. Mitteilung. Wiener Archiv für innere Medizin und deren Grenzgebiete, II, 425.

Requests for reprints to Professor F. Franchi, Via J. Naroli 10, 50132 Firenze, Italy. 